\title{
Provide GPs with spirometry, not spirometers
}

\section{Paul Enright}

Investigators from Tasmania, an island state of Australia (famous for its marsupial devils), have demonstrated, in this issue of Thorax, ${ }^{1}$ that both the quantity and quality of spirometry tests provided by nurses visiting general practitioner (GP) offices were much better than when GPs were given a spirometer and taught when and how to use it (see page 408). The visiting (peripatetic or itinerant) nurses tested $59 \%$ of the target group of ever smokers over the age of 35 years, compared with only $8 \%$ tested by the GPs with their own spirometer. Quality goals for spirometry were met by $76 \%$ of the tests done by the nurses but only by $44 \%$ of the tests done by the GPs.

In this issue of Thorax, a study is described in which investigators from Poland $^{2}$ offered spirometry testing by visiting nurses to all 2250 adult patients over the age of 39 years in the practice of a single GP (see page 402). Over $87 \%$ of the target group responded by scheduling a visit to the office for spirometry testing. Post-bronchodilator (post-BD) spirometry was done for those with airway obstruction pre-BD. Quality goals for spirometry were met for $92 \%$ of the tests. Post-BD airway obstruction, consistent with chronic obstructive pulmonary disease (COPD), was detected in $9 \%$ of patients.

We know that COPD is usually not detected in smokers until more than half of their lung function has been irretrievably lost, and frequently not until a severe exacerbation causes hospitalisation. ${ }^{3}$ Yet our efforts during the past 20 years to encourage GPs to regularly use office spirometers to test their high risk patients have been bedevilled by very low utilisation and poor quality, ${ }^{4-6}$ even when given free training, free spirometers and reimbursement for their time.

Not only is COPD greatly underdiagnosed, but it is also unconfirmed or overdiagnosed by primary care practitioners - at least in the USA, where twothirds of those given the diagnosis and prescribed an inhaler have not had a spirometry test. ${ }^{78}$ Even the few GPs who

Correspondence to: Dr Paul Enright, University of Arizona, 4460 East Ina Rd, Tucson, AZ 85718, USA; lungguy@aol.com routinely perform spirometry in their own office do not take the time to confirm airway obstruction post-BD. Approximately one-third of smokers with preBD airway obstruction do not have it post-BD. ${ }^{9}$ Using the fixed 0.70 threshold in people over the age of 50 years, or labelling those with a normal forced expiratory volume in $1 \mathrm{~s}\left(\mathrm{FEV}_{1}\right)$ as having COPD causes high false positive rates ${ }^{10}$ and is counterproductive. The resulting high COPD misclassification rates have costly personal and community consequences. ${ }^{11}$

What is the most practical solution to this problem? Simple COPD screening questions should be completed by as many smokers as possible, ${ }^{12-14}$ perhaps using newspapers, magazines and the internet. In countries where biomass fuel is commonly used with poor venting for cooking or heating, never smoking women are also at an increased risk for COPD. Those with a high pre-test probability for COPD should be offered spirometry, or at least a peak expiratory flow measurement. Those with a low peak expiratory flow using a mechanical meter, or a low $\mathrm{FEV}_{1} /$ forced vital capacity and low $\mathrm{FEV}_{1}$ from a good quality pre-BD spirometry test should then be tested post-BD using spirometry to confirm moderate to severe airway obstruction before considering a prescription for a COPD inhaler. ${ }^{15}$ Both of the current studies $^{12}$ probably would have shown a lower cost per new case of COPD detected if a screening questionnaire (instead of only age and/or smoking status) had been used to determine which patients really needed spirometry testing.

All smokers, regardless of spirometry results, should be advised to quit and helped to quit using effective new medications when self-help is not good enough. ${ }^{16}$ When presented with interpreted spirometry results, GPs usually make the appropriate diagnostic and treatment decisions. ${ }^{17-20}$ However, the problem remains: who is going to do all of these spirometry tests, when and where?

Our colleagues in Poland first began offering a better solution for the widespread detection and confirmation of COPD in 1999 by providing spirometry testing done by trained and experienced technologists using an accurate spirometer in convenient locations at convenient times. ${ }^{21}$ The spirometry tests were widely advertised, usually offered once a week at an outpatient clinic in each city, with all costs paid by the department of health, but only pre-BD testing was offered. At 60 sites, over 100000 tests have been done by this programme in Poland, and relatively good rates of smoking cessation have been confirmed in subsamples with followup. $^{22} 23$ The new study from Poland ${ }^{2}$ demonstrates that pre-BD and post-BD spirometry, offered by trained nurses at conveniently scheduled times at the office of a GP, efficiently and accurately detects COPD in adult patients (and confirms asthma in others).

At the Charing Cross Hospital in London, an "open access spirometry service" for 33 local GPs morphed into a "Community Respiratory Assessment Unit". ${ }^{24}$ High levels of satisfaction were reported by patients and GPs during the first year. In addition to pre-BD spirometry testing provided by the Tasmanian study, the specialist nurses in London provided important additional services: post-BD spirometry when pre-BD results were abnormal, succinct spirometry interpretations back to the referring GP and 1 page educational materials on smoking, COPD and asthma. When indicated, they also checked oxygen saturation, reviewed and improved each patient's inhaler techniques and provided help with smoking cessation.

A continuous quality improvement programme for spirometry must be implemented to minimise misclassification. The quality of all of the spirometry tests done by allied health professionals should be monitored and reported at least monthly by a pulmonary function expert. Those who cannot meet quality goals for at least eight of every 10 tests need retraining. The pulmonary function expert should also select the reference equations and conservative interpretation scheme used by the programme.

Twenty years ago, pulmonary specialists realised that GPs were not sending patients to hospital based PFT laboratories and therefore the response was to encourage GPs to purchase office spirometers. Although the price, size, quality, accuracy and features of office spirometers have dramatically improved, ${ }^{11}$ only a small fraction of GPs in most countries both purchase and regularly use office spirometers because of many barriers. ${ }^{25}$ 
The projects from Tasmania, Poland and the UK provide great examples of a better alternative: provide GPs with high quality spirometry services for high risk patients. These can be scheduled at convenient times every 1-6 weeks in each GP office, or at locations in each community with easy access.

Competing interests: None.

Thorax 2008;63:387-388. doi:10.1136/thx.2007.092916

\section{REFERENCES}

1. Walters JA, Hansen EC, Johns DP, et al. A mixed methods study to compare models of spirometry delivery in primary care for patients at risk of COPD. Thorax 2008;63:408-14.

2. Bednarek M, Maciejewski J, Wozniak M, et al. Prevalence, severity and underdiagnosis of COPD in the primary care setting. Thorax 2008;63:402-7.

3. Zoia MC, Corsico AG, Beccaria M, et al. Exacerbations as a starting point of pro-active chronic obstructive pulmonary disease management. Respir Med 2005;99:1568-75.

4. den Otter JJ, de Bryuyn-Schmidt MA, Wolters MJ et al. Lung function measurement in general practice: General practice measurements compared with laboratory measurements during the DIMCA trial. Fam Pract 2000;17:314-16.

5. Kaminsky DA, Marcy TW, Bachand M, et al. Knowledge and use of office spirometry for the detection of chronic obstructive pulmonary disease by primary care physicians. Respir Care 2005;50:1639-48.
6. Lusuardi M, De Benedetto F, Paggiaro P, et al. A randomized controlled trial on office spirometry in asthma and COPD in standard general practice: data from spirometry in asthma and COPD: a comparative evaluation Italian study. Chest 2006:129:844-52.

7. Lee TA, Bartle B, Weiss KB. Spirometry use in clinical practice following diagnosis of COPD. Chest 2006:129:1509-15.

8. Han MK, Kim MG, Mardon R, et al. Spirometry utilization for COPD: how do we measure up? Chest 2007:132:403-9.

9. Perez-Padilla R, Hallal PC, Vazquez-Garcia JC, et al, on behalf of the PLATINO group. Impact of bronchodilator use on the prevalence of COPD in population-based samples. COPD 2007:4:113-20.

10. Hnizdo E, Glindmeyer HW, Petsonk EL, et al. Case definitions for chronic obstructive pulmonary disease. COPD 2006;3:95-100.

11. Enright PL, Studnicka M, Zielinski J. Spirometry to detect and manage COPD and asthma. Eur Respir Mon 2005;31:1-14.

12. Mullerova H, Wedzicha J, Soriano JB, et al Validation of a chronic obstructive pulmonary disease screening questionnaire for population surveys. Respir Med 2004:98:78-83.

13. Calverley PM, Nordyke RJ, Halbert RJ, et al Development of a population-based screening questionnaire for COPD. COPD 2005;2:225-32.

14. Price DB, Tinkelman DG, Nordyke RJ, et al, COPD Questionnaire Study Group. Scoring system and clinical application of COPD diagnostic questionnaires. Chest 2006:129:1531-9.

15. AHRO Minnesota Evidence-based Practice Center of the Agency for Healthcare Research and Quality. Use of Spirometry for Case Finding, Diagnosis, and Management of COPD. Publication No 05-E017-2,
August 2005. http://www.ahrq.gov/clinic/tp/ spirotp.htm (accessed 3 March 2008)

16. Tonnesen P, Carrozzi L, Fagerstrom KO, et al. Smoking cessation in patients with respiratory diseases: a high priority, integral component of therapy. Eur Respir J 2007;29:390-417.

17. Buffels J, Degryse J, Heyrman J, et al. Office spirometry significantly improves early detection of COPD in general practice. The DIDASCO study. Chest 2004; 125:1394-9

18. Chavannes N, Schermer T, Akkermans R, et al. Impact of spirometry on GPs' diagnostic differentiation and decision-making. Respir Med 2004:98:1124-30.

19. Walker PP, Mitchell P, Diamantea F, et al. Effect of primary-care spirometry on the diagnosis and management of COPD. Eur Respir J 2006;28:945-52.

20. Yawn BP, Enright PL, Lemanske RF Jr, et al. Spirometry can be done in family physicians' offices and alters clinical decisions in management of asthma and COPD. Chest 2007;132:1162-8.

21. Zielinski J, Bednarek M, Know the Age of Your Lung Study Group. Early detection of COPD in a high-risk population using spirometric screening. Chest 2001;119:731-6.

22. Zielinski J, Bednarek M, Gorecka D, et al. Increasing COPD awareness. Eur Respir J 2006:27:833-52.

23. Bednarek M, Gorecka D, Wielgomas J, et al. Smokers with airway obstruction are more likely to quit smoking. Thorax 2006;61:869-73.

24. Hassett R, Meade K, Partridge MR. Enhancing the accuracy of respiratory diagnoses in primary care: a report on the establishment of a Community Respiratory Assessment Unit. Prim Care Respir J 2006;15:354-61.

25. Walters J, Hansen E, Mudge P, et al. Barriers to the use of spirometry in general practice. Aust Fam Physician 2005;34:201-3.

\section{The evidence based treatment of tuberculosis: where and why are we failing?}

\section{Lawrence Peter Ormerod}

\section{THE SCALE OF THE PROBLEM}

Tuberculosis is increasing both globally and nationally, so its management is becoming even more important. Globally, it is estimated that there are at least 7.96 million $(95 \%$ confidence interval 6.3-11.1) clinical cases, with 3.52 million (2.8-4.1) sputum microscopy positive cases, and 1.87 million (1.4-2.8) deaths. ${ }^{1}$ This gives a case fatality rate of $23 \%$. In addition, $32 \%$ of the world's population (1.86 billion) are infected, as judged by a positive tuberculin skin test. ${ }^{1}$ In England and Wales after a nadir of 5000 cases per year, numbers have reached over $8000 .^{2}$

Correspondence to: Professor Lawrence L Peter Ormerod, Royal Blackburn Hospital, Lancs BB2 3HH, UK; Lawrence.Ormerod@elht.nhs.uk

\section{THE SCIENTIFIC BASIS FOR SHORT COURSE CHEMOTHERAPY}

Each of the antituberculosis drugs vary in their abilities to kill organisms, to sterilise lesions and to prevent the emergence of drug resistance. ${ }^{3}$ Isoniazid is the best drug for killing rapidly dividing organisms, followed by rifampicin and then streptomycin and ethambutol. Rifampicin is best for dormant organisms with occasional spurts of metabolism, and pyrazinamide is best for organisms in an intracellular (acid) environment. Multiple controlled clinical trials have been carried out in a number of countries. ${ }^{3}$ These show that a 6 month regimen comprising a 2 month phase of rifampicin $(\mathrm{R})$, isoniazid $(\mathrm{H})$, pyrazinamide ( $Z$ ) and ethambutol (E), followed by a 4 month continuation phase of rifampicin and isoniazid, designated 2RHZE/4HR, gives a greater than $95 \%$ cure rate, and a relapse rate of less than $5 \%$. This applies whether the drugs are given daily throughout treatment, daily in the initial phase with an intermittent (thrice weekly) continuation phase or fully intermittent throughout. $^{3}$ If the regimen is shortened to 4 months by a shortened continuation phase, relapse rates rise to over $10 \%{ }^{4}$ The 6 month short course regimen also performs well in the presence of a proportion of isoniazid and/or streptomycin resistance, but much less well if there is initial rifampicin resistance. ${ }^{5}$ The fourth drug in the initial phase, ethambutol, is included to cover the possibility of drug resistance. Six month short course regimens have performed well in England and Wales in both clinical trial conditions, with relapse rates of $1-3 \%,{ }^{6}$ and in routine clinical practice with relapse rates of $0-4 \% .^{78}$ Monitoring of the treatment used in patients with pulmonary disease in the 1983 and 1988 national surveys showed a big change towards pyrazinamide containing regimens, but this was not accompanied in many cases by the appropriate reduction of treatment duration to 6 months that this change allowed. ${ }^{9}$ 